\title{
Recent incidence of collar canker and dieback of tea (Camellia sinensis) caused by Fusarium solani species complex in Sri Lanka
}

\author{
Ganga D. Sinniah ${ }^{1} \cdot$ Chanushka E. Munasinghe $^{2} \cdot$ Niranjan Mahadevan $^{1}$. \\ Samodya K. Jayasinghe ${ }^{1}$. Dalawellage C. M. Kulatunga ${ }^{1}$
}

Received: 30 June 2016 / Accepted: 24 July 2017 /Published online: 19 August 2017

(C) Australasian Plant Pathology Society Inc. 2017

\begin{abstract}
A collar canker and dieback disease of tea has recently emerged in Sri Lanka. Isolation from cankers consistently yielded fusaria. Morphological characters and ITS and tefl combined sequence analysis identified the selected isolates as members of Fusarium solani Species Complex Clade 3. Artificial inoculation to young and mature tea plants confirmed pathogenicity.
\end{abstract}

Keywords Ambrosia Fusarium clade · Fusarium ambrosium $\cdot$ Fusarium pseudensiforme $\cdot$ Phylogenetic analysis $\cdot$ tef1

Tea (Camellia sinensis) is the major plantation crop in Sri Lanka contributing about $15 \%$ of total export earnings. Canker is the most widely prevalent stem disease of tea worldwide. Cankers are persistent, attacking twigs, stems and killing or girdling branches ultimately leading to death of tea bushes.

Phomopsis theae has been identified as the major pathogen causing stem canker disease in Japan (Kasai et al. 1965), India (Venkata Ram 1979), China (Chen and Chen 1982), Kenya (Onsando 1988) and Bangladesh (Ahmad et al. 2013). In Sri

Electronic supplementary material The online version of this article (doi:10.1007/s13314-017-0262-5) contains supplementary material, which is available to authorized users.

Ganga D. Sinniah

gdsinniah@gmail.com

1 Plant Pathology Division, Tea Research Institute of Sri Lanka, Talawakelle 22100, Sri Lanka

2 Advisory and Extension Division, Mid Country Regional Centre, Tea Research Institute of Sri Lanka, Hantane, Kandy 20000, Sri Lanka
Lanka, Macrophoma theicola and Botryodiplodia theobromae (Sabanayagam et al. 1974) are the major canker causing pathogens in the low $(<600 \mathrm{~m}$ mean sea level) and mid-elevations (1200-600 m mean sea level) whereas $P$. theae is problematic in the high elevations ( $>1200 \mathrm{~m}$ mean sea level) (Balasuriya 2008). Liyanage et al. (2013) reported Fusarium solani as a canker causing agent for the first time in the low elevation tea growing areas of Sri Lanka. Recently in Sri Lanka, the incidence of collar canker and associated bush dieback has become widespread. This study aimed at identifying the causal organism in different tea growing regions.

Dieback incidence in affected fields ranged from 50 to $85 \%$. The affected tea bushes had fewer and smaller leaves, yellowing of leaves and premature falling. Heavy flowering and fruiting commonly followed canopy thinning. Progressive dieback of branches resulted in bare bushes (Fig. 1a). Foliar symptoms were always associated with cankers having cracks and peeling of bark at the collar region. The exposed cambium and wood were discoloured, tan, brown or black. Cankers at the collar region were irregular in shape and extended to several centimetres in length and depth (Fig. 1b). Reddish, tiny superficial perithecia were seen under damp and moist conditions (Fig. 1c). Fibrous root formation just above the cankered area was also observed.

Symptomatic samples were collected from tea fields covering a range of rainfall and elevation during the period 20132014. Pieces $\left(3-5 \mathrm{~mm}^{3}\right)$ of tissue from the margin of canker lesions were separately plated on Fusarium selective pentachloronitrobenzene (PCNB) medium (Papavizas 1967), potato dextrose agar (PDA, Oxoid), and malt extract agar (MEA, Oxoid) supplemented with tetracycline $(10 \mathrm{mg} / \mathrm{ml})$. Fungi were allowed to grow for seven days in the dark at room temperature $\left(22 \pm 2{ }^{\circ} \mathrm{C}\right)$, sub-cultured and purified on PDA. The isolates identified as fusaria were grown on carnation leaf agar (CLA) at $27^{\circ} \mathrm{C}$ to stimulate conidia development (Fisher 
Fig. 1 a Tea bush naturally affected by collar canker and dieback (b) natural infection showing the prominent canker at the collar region (c) perithecia on an infected tea bush (d) necrotic tissue beneath the point of artificial inoculation (note the bark has been removed to expose internal tissue browning)
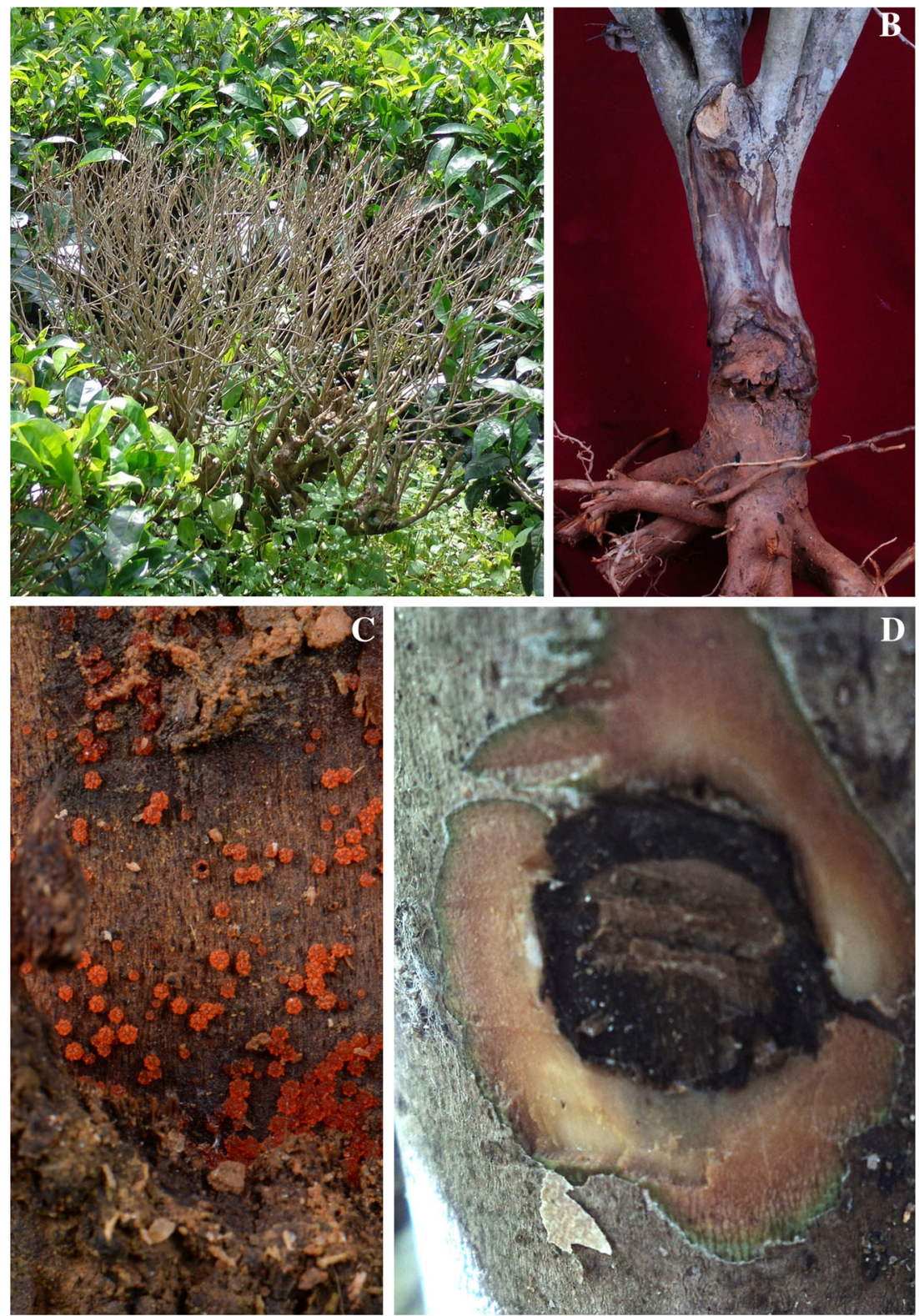

et al. 1982). The colony characters of Fusarium isolates were compared with diagnostic characteristics specified by Leslie and Summerell (2006) and Nirenberg and O'Donnell (1998). Selected isolates were deposited at the International Collection of Microorganisms from Plants (ICMP).

Four isolates were selected for molecular characterisation, being one from Ruwanwella (ICMP 21513), one from Norton (ICMP 21515), and two from Yatinuwara (ICMP 21518, ICMP 21519). DNA was extracted using a DNeasy plant mini extraction kit (Qiagen) from mycelium of 7-10 days old monoconidial cultures grown on PDA. Internal transcribed spacer regions and intervening 5.8S rRNA gene (ITS) of the rDNA operon were amplified using the primer pair ITS-1F (5'-CTTGGTCATTTAGAGGAAGTAA-3') / ITS-4 (5'-
TCCTCCGCTTATTGATATGC-3'), and PCR conditions of White et al. (1990). Translation elongation factor 1- $\alpha$ (tefl) was amplified using the primer pair EF-1 (5'-ATGG GTAAGGA (A/G)GACAAGAC-3') / EF-2 (5' GGA(G/A)GTACCAGT(G/C)ATCATGTT-3'), following PCR conditions described by O'Donnell et al. (1998). Amplicons of about $560 \mathrm{bp}$ and $700 \mathrm{bp}$ (ITS and tef1, respectively) were sequenced through Macrogen (Korea) and deposited in GenBank (Accession No KJ009327 to KJ009330, KR707726 to KR707729).

Sequences generated in this study and others obtained from GenBank (Table 1), composed two datasets (ITS and tef1) which were separately aligned using Mafft v.7 (http://mafft. cbrc.jp/alignment/server/index.html). Ambiguous regions 
Table 1 Sequences used in the phylogenetic analysis, newly generated sequences are in bold

\begin{tabular}{|c|c|c|c|c|c|}
\hline \multicolumn{2}{|c|}{ GenBank accession number } & \multirow[t]{2}{*}{ Species } & \multirow[t]{2}{*}{ Isolate/strain ${ }^{*}$} & \multirow[t]{2}{*}{ Host } & \multirow[t]{2}{*}{ Reference } \\
\hline ITS & TEF & & & & \\
\hline KJ009328 & KR707729 & Fusarium sp. & ICMP 21513 & Camellia sinensis & In this study \\
\hline KJ009327 & KR707727 & Fusarium sp. & ICMP 21515 & Camellia sinensis & In this study \\
\hline KJ009330 & KR707728 & Fusarium sp. & ICMP 21518 & Camellia sinensis & In this study \\
\hline KJ009329 & KR707726 & Fusarium sp. & ICMP 21519 & Camellia sinensis & In this study \\
\hline JX173101 & - & F. solani & $\mathrm{AF} 14$ & Aquilaria malaccensis & Premalatha and Kalra 2013. \\
\hline JQ723751 & JQ723758 & F. solani & UCR1785 & Persea americana & Eskalen et al. 2012 \\
\hline AF178408 & AF178344 & F. solani f. sp. batatas & NRRL 22402 & Unknown & O'Donnell 2000 \\
\hline AF178419 & AF178357 & F. solani f. sp. glycines & NRRL 22825 & Unknown & O'Donnell 2000 \\
\hline KM406631 & KM406624 & F. ambrosium & NRRL 62942 & Tea Shot Hole borer & O’Donnell et al. 2015 \\
\hline KC691559 & КC691531 & F. ambrosium & NRRL 62605 & Tea Shot Hole borer & Kasson et al. 2013 \\
\hline JX891747 & JX891859 & F. euwallaceae & FD31 PEAM & Persea americana & Eskalen et al. 2013 \\
\hline AY220236 & AY220187 & F. phaseoli & NRRL31156 & Glycine max & Aoki et al. 2003 \\
\hline KM406635 & KM406628 & Fusarium sp. & NRRL 62943 & Camellia sinensis & O’Donnell et al. 2015 \\
\hline KM406634 & KM406627 & Fusarium sp. & NRRL 62944 & Camellia sinensis & O’Donnell et al. 2015 \\
\hline JQ038019 & JQ038012 & Fusarium sp. & NRRL 54727 & Persea americana & Freeman et al. 2013 \\
\hline AF178402 & AF178338 & F. cf. ensiforme & NRRL 22354 & Unknown & Kasson et al. 2013 \\
\hline KC691584 & KC691555 & F. pseudensiforme & NRRL 46517 & Unknown & Kasson et al. 2013 \\
\hline AF178423 & AF178361 & F. staphyleae & NRRL 22316 & Unknown & O'Donnell 2000 \\
\hline AF178421 & AF178359 & Nectria haematococca MPIII & NRRL 22157 & Unknown & O'Donnell 2000 \\
\hline AF178401 & AF178336 & N. haematococca MPIV & NRRL 22277 & Zanthoxylum sp. & O'Donnell 2000 \\
\hline AF178411 & AF178347 & N. haematococca MPV & NRRL 22142 & Cucurbita sp. & O'Donnell 2000 \\
\hline AB513852 & AB513842 & N. haematococca MPVI & MAFF 840047 & Morus alba & Nakayama and Aoki 2010 \\
\hline AF178395 & AF178330 & N. haematococca MPVII & NRRL 22161 & Robinia pseudoacacia & O'Donnell 2000 \\
\hline AB513849 & AB513845 & N. ipomoeae & MAFF 238974 & Passiflora edulis & Nakayama and Aoki 2010 \\
\hline AF178393 & AF178326 & N. illudens & NRRL 22090 & Unknown & O'Donnell 2000 \\
\hline
\end{tabular}

*NRRL Culture collection of Agricultural Research Service, USA

ICMP International Collection of Microorganism from Plants

$M A F F$ Culture collection of Ministry of Agriculture, Forestry and Fisheries, Tsukuba, Ibaraki, Japan

Others indicate collectors' codes

were removed and, whenever necessary, the alignments were manually improved. The individual and combined ITS and tefl sequences were subjected to a Maximum Likelihood analysis (ML) using RaxMLGUI version 1.3.1 (Silvestro and Michalak 2012). The optimal ML tree search was conducted with 1000 separated runs, using the default algorithm of the program, from a random starting tree for each run. The final tree was selected among sub optimal trees, from each run, under the GTR $+\mathrm{G}$ substitution model. The resulting tree was edited and printed with TreeGraph 2 v. 2.11.1 (Stöver and Müller 2010).

Pathogenicity tests were carried out on vegetatively propagated 1 year and 10 years old tea plants (cv TRI 2023) with the selected isolates, ICMP 21513, ICMP 21515, ICMP 21518 and ICMP 21519. Each isolate/control was inoculated on to ten replicate plants. A wound (5 $\mathrm{mm}$ diameter) was made on the main stems of test and control plants by removing the bark with a cork borer. Test plants were inoculated by placing a mycelia plug ( $5 \mathrm{~mm}$ in diameter) cut from the margins of seven-day-old monoconidial cultures of each isolate, on the wounds. Control plants were inoculated with sterile PDA plugs without mycelia. The plants were maintained under recommended nursery or field conditions for tea plants. The pathogen was re-isolated from lesions after development of symptoms.

Ninety percent of 96 isolates obtained from symptomatic tissues were fusaria. The 4 selected isolates were identified as the members of Fusarium solani species complex (FSSC) based on morphological characters (Fig. 2 A-F, supplementary data) and analysis of two DNA loci (ITS and tefl). The 
Fig. 2 Colony on PDA of (a) ICMP 21515 (b) ICMP 21518 (c) ICMP 21513 and (d) ICMP 21519, (e) micro and macro conidia of ICMP 21519 (f) perithecia of ICMP 21513 on PDA
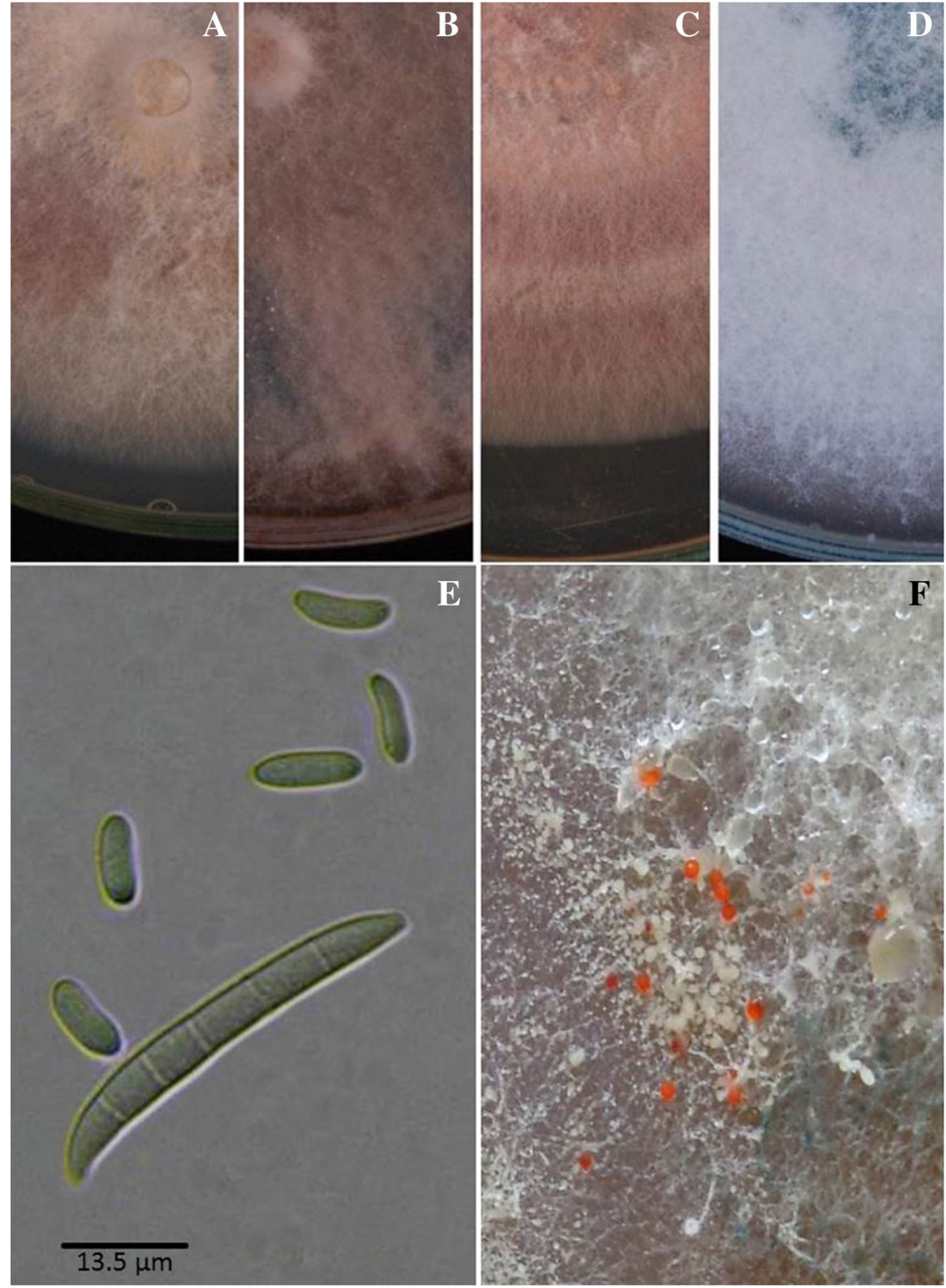

combined phylogenetic analysis (Fig. 3) revealed that all 4 isolates from tea belonged to FSSC clade 3 (O'Donnell 2000). Two isolates (ICMP 21513 and ICMP 21518) formed a sub-cluster within the Ambrosia Fusarium Clade (AFC), together with $F$. pseudensiforme NRRL 46517 (Kasson et al. 2013) and F. cf. ensiforme NRRL 22354 (Kasson et al. 2013). The isolates ICMP 21519 and ICMP 21515 clustered on a distinct clade, together with F. solani AF14 and Nectria haematococca (Fig. 3).

The AFC includes symbiont fusaria associated or not with ambrosia beetles (Kasson et al. 2013). Fusarium ambrosium is a symbiont of the Tea shot-hole bore (TSHB), Euwallacea fronicatus (= Xyleborous fornicatus), a serious pest of tea in India and Sri Lanka (Gadd and Loos 1947). Fusarium pseudensiforme and $F$. cf. ensiforme are not known to be associated with ambrosia beetle (Nalim et al. 2011; Kasson et al.
2013). These two species and the isolates associated with collar canker and dieback of tea differ from $F$. ambrosium by having typical fusiform macroconidia, the latter produces a clavate macroconidia (Gadd and Loos 1947). Members of $N$. haematococca are also economically important plant pathogens causing root rot, fruit rot and dieback in important plant species (O’Donnell 2000).

The occurrence of isolates belonging to the AFC and $N$. haematococca clade indicate the genetic variability of the casual agents of collar canker and dieback of tea. Artificial inoculation of the selected isolates from each group resulted in prominent cankers in $50-80 \%$ of the nursery plants and 70 $90 \%$ of the field plants, confirming its pathogenicity (Fig. 1d). This study identified causal agents of collar canker and dieback of tea in Sri Lanka to be members of FSSC clade 3 and established the existence of diversity among the isolates. The 
Fig. 3 Best scoring RAxML tree of Fusaria obtained from concatenate sequence alignment of ITS and tefl region. The scale bar shows 0.02 substitutions per site and bootstrap replicate values from 1000 replicates are shown next to the branches. Isolates obtained in this study are in bold

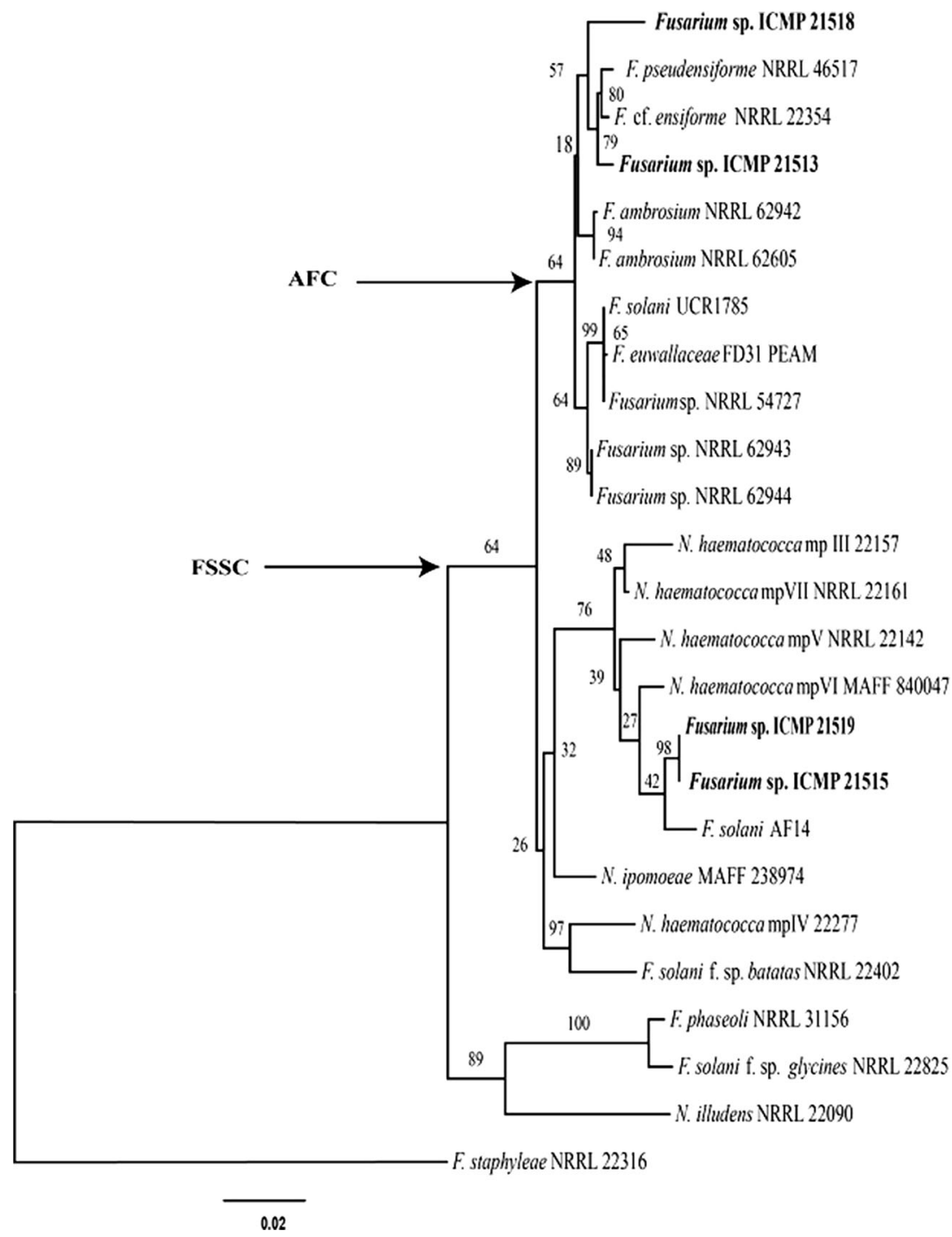

0.02

information generated will help to develop intervention strategies and efforts to reduce the economic impact of this recently emerged disease of tea.

Acknowledgements We sincerely acknowledge the support given by the Tea small holders of the study sites. We also thank Mr. JCK Rajasinghe, Principle Advisory Officer, Tea Research Institute for the support and valuable suggestions and Drs. S Maharachchikumbura and KPRN Athanayake for the assistance in the analysis of molecular data. Tea Research Institute of Sri Lanka is acknowledged for the funding of project $\mathrm{D} / \mathrm{P} / \mathrm{Pa} / 1$.

\section{References}

Ahmad A, Md O, Hossain MA, Ali M, Islam Md S (2013) In vitro biological control of branch canker (Macrophoma theiocola) disease of tea. Int J Phytopathol 2:163-169

Aoki T, O'Donnell K, Homma Y, Lattanzi AR (2003) Sudden-death syndrome of soybean is caused by two morphologically and phylogenetically distinct species within the Fusarium solani species
complex-F. virguliforme in North America and F. tucumaniae in South America. Mycologia 95:660-684

Balasuriya A (2008) Common diseases of tea and their management. In: Zoysa AKN (ed) Handbook on tea. Tea Research Institute of Sri Lanka, Talawakelle, pp 173-209

Chen TM, Chen SF (1982) Diseases of tea and their control in the people's republic of China. Plant Dis 66:961-965

Eskalen A, Gonzalez A, Wang DH, Twizeyimana M, Mayorquin JS, Lynch SC (2012) First report of a Fusarium sp. and its vector tea shot hole borer (Euwallacea fornicatus) causing Fusarium dieback on avocado in California. Plant Dis 96:1070

Eskalen A, Stouthamer R, Lynch SC, Rugman-Jones PF, Twizeyimana M, Gonzalez A, Thibault T (2013) Host range of fusarium dieback and its ambrosia beetle (Coleoptera: Scolytinae) vector in Southern California. Plant Dis 97:938-951

Fisher NL, Burgess LW, Toussoun TA, Nelson PE (1982) Carnation leaves as a substrate and for preserving cultures of Fusarium species. Phytopathology 72:151-153

Freeman S, Sharon M, Maymon M, Mendel Z, Protasov A, Aoki T, Eskalen A, O'Donnell K (2013) Fusarium euwallaceae sp. nov.-a symbiotic fungus of Euwallacea sp., an invasive ambrosia beetle in Israel and California. Mycologia 105: $1595-1606$ 
Gadd CH, Loos CA (1947) The ambrosia fungus of Xyleborus fornicatus Eich. Trans Br Mycol Soc 30:13-18

Kasai K, Hirokawa S, Takaya S, Kibushi H (1965) Factors affecting the occurrence of die-back and canker disease of tea. Tea Res J 23:3958

Kasson MT, O’Donnell K, Rooney AP, Sink S, Ploetz RC, Ploetz JN, Konkol JL, Carrillo D, Freeman S, Mendel Z, Smith JA, Black AW, Hulcr J, Bateman C, Stefkova K, Campbell PR, Geering ADW, Dann EK, Eskalen A, Mohotti K, Short DPG, Aoki T, Fenstermacher KA, Davis DD, Geiser DM (2013) An inordinate fondness for Fusarium: phylogenetic diversity of fusaria cultivated by ambrosia beetles in the genus Euwallacea on avocado and other plant hosts. Fungal Genet Biol 56:147-157

Leslie JF, Summerell BA (2006) The Fusarium laboratory manual. Blackwell Publishing Professional, Iowa

Liyanage NHP, Jagathpriya Weerasena OVDS, Liyanaarachchi CJ, Wijesundera RLC, Abeysinghe SB, Reeder R (2013) Recent emergence of Fusarium dieback of tea (Camellia sinensis) in Sri Lanka and its potential link with tea shot hole borer (Euwallacea fornicates). The $19^{\text {th }}$ Australasian plant pathology conference. Auckland, New Zealand, p 80

Nakayama K, Aoki T (2010) Foot rot of tomato, a new disease in Japan, caused by Fusarium solani f. Sp. eumartii. Jpn J Phytopathol 76:716

Nalim FA, Samuels GJ, Wijesundera RL, Geiser DM (2011) New species from the Fusarium solani species complex derived from perithecia and soil in the old world tropics. Mycologia 103:1302-1330

Nirenberg HI, O’Donnell K (1998) New Fusarium species and combinations within the Gibberella fujikuroi species complex. Mycologia 90:434-458

O’Donnell K, Kistler HC, Cigelnik E, Ploetz RC (1998) Multiple evolutionary origins of the fungus causing Panama disease of banana: concordant evidence from nuclear and mitochondrial gene genealogies. Proc Natl Acad Sci U S A 95:2044-2049
O’Donnell K, Sink S, Libeskind-Hadas R, Hulcr J, Kasson MT, Ploetz RC, Konkol J, Ploetz JN, Carrillo D, Campbell A, Duncan RE, Liyange PNH, Eskalen A, Na F, Geiser DM, Bateman C, Freeman S, Mendel Z, Sharon M, Aoki T, Cosse AA, Rooney AP (2015) Discordant phylogenies suggest repeated host shifts in the Fusarium-Euwallacea Ambrosia beetle mutualism. Fungal Genet Biol 82:277-290

O'Donnell K (2000) Molecular phylogeny of the Nectria haematococcaFusarium solani species complex. Mycologia 92:919-938

Onsando JO (1988) Tea diseases situation in Kisii District. Tea 9:47-49

Papavizas GC (1967) Evaluation of various media and antimicrobial agents for isolation of Fusarium from soil. Phytopathology 57: $848-852$

Premalatha K, Kalra A (2013) Molecular phylogenetic identification of endophytic fungi isolated from resinous and healthy wood of Aquilaria malaccensis, a red listed and highly exploited medicinal tree. Fungal Ecol 6:205-211

Sabanayagam JV, Samarakoon HH, Shanmuganathan N (1974) Susceptibility of some tea clones to stem canker caused by Macrophoma theicola Petch in the low country. Tea Quart 44:74-78

Silvestro D, Michalak I (2012) raxmlGUI: a graphical front-end for RAxML. Org Divers Evol 12:335-337

Stöver BC, Müller KF (2010) TreeGraph 2: combining and visualizing evidence from different phylogenetic analyses. BMC Bioinformatics 11:7. doi:10.1186/1471-2105-11-7

Venkata Ram CS (1979) Phomopsis collar canker-a limiting factor to use of clonal material. In: Venkataram CS (ed) Plant protection (entomology, microbiology, nematology, plant pathology and Rodentology). Indian Soc Plantation Crops, Kerala, India, pp 146151

White TJ, Bruns TD, Lee S, Taylor JW (1990) Amplification and direct sequencing of fungal ribosomal RNA genes for phylogenetics. In: Innis MA, Gelfand DH, Sninsky JJ, White TJ (eds) PCR protocols: a guide to methods and applications. Academic, San Diego, pp 315322 